\title{
BANCROFTIAN FILARIASIS IN SRI LANKA: AN OVERVIEW OF CURRENT KNOWLEDGE
}

\author{
SENARATH DISSANAYAKE \\ Department of Biochemistry, Faculty of Medicine, University of Peradeniya, Peradeniya, \\ Sri Lanka.
}

AND

NALINI JAYASEKERA

Department of Entomology, Medical Research Institute, Colombo, Sri Lanka.

(Date of receipt : 28 March 1988)

(Date of acceptance : 02 August 1989)

\begin{abstract}
Bancroftian frlariasis is a major public health problem. in Sri Lanka, where approximately one fifth of the total population in the country living in the most densely populated Western and Southern provinces are considered to be at risk of developing the infection. Available historical evidence indicate that Bancroftian filariasis was introduced to Sri Lanka in the 15 th century AD. The role of the AntiFilariasis Campaign which was inaugurared for the purpose of controlling filariasis in the country is discussed. Also the available literature on entomological and epidemiological aspects of the disease is reviewed.
\end{abstract}

\section{Introduction}

Of the filarial parasites infecting man, eight species can be considered as truely specific for man. They are Wuchereria bancrofti, Brugia malayi (periodic) Brugia timori, Onchocerca volvulus, Loa loa, Mansonella ozzardi, Tetrapetalonema perstans and Tetrapetalonema streptocerca. Natural infections in animals with these species are rare, nonexistent or uncertain but few species may be maintained in laboratory animals. ${ }^{25}$

- usease caused dy Tilarial infections is a püblic hèalth problem in isn Lanka. Approximately one fifth of the total population in the country; living in the most densely populated Western and Southern provinces are considered at risk of developing the infection. Filariasis in Sri Lanka today is due to $W$. bancrofti. Brugian filariasis (due to $B$. malayi infections), which was prevalent in 1930-1950's, is believed to be non-existent now.

\section{Historical Aspects}

The first reported cases of filariasis in Sri Lanka were from the Central Province, where endemic filarial infections are rare as at today. Ondatje 7 reported two clinical cases of elephantiasis from Matale hospital and one from Kandy hospital. Angther case was reported by Kynsey ${ }^{48}$ from Matara. The earliest record of microfilaraemia in a patient in Sri Lanka was from Matara hospital in $1893 .^{20}$ 
According to Abdulcader, ${ }^{4}$ available historical evidence was in support, of the view that filariasis due to B. malayi was introduced to Sri Lanka in the 12th/ 13th centuries A.D. as a result of Kalinga invasions and bancroftian filariasis in the 15 th century A.D. by a Chinese army.

In 1947, when the Anti Filariasis Campaign (AFC) of Sri Lanka was inaugurated for the specific purpose of controlling fitarial infections, the problem of Brugian filariasis was limited to approximately 380 square miles of area. The population at risk was estimated at about 120,000. The $\mathrm{mf}$ rates varied between $1.3 \%$ (Weeraketiya and Bingiriya) to $18 \%$ in Toppur. ${ }^{4}$ The successful control of Brugian filariasis was probably due to the combined effects of Pistia control by weedicide (Phenoxylene 30) spray, mosquito control measures of the Anti Malaria Campaign and new case findings and treatment of microfilaraemics by the AFC. ${ }^{21}$

In the course of 7-8 years of control work, the Brugian $\mathrm{mf}$ rate had dropped to about $1 \%$ in all foci. At this stage (year 1957) the programme was terminated. Although it is believed that Brugian filariasis does not exist in Sri Lanka, it must be noted that the vector (Mansonia mosquitoes) continue to breed in many areas. The detection of ${ }^{2}$ Brugia infections by Dissanaike $^{24}$ makes it premature to conclude that Brugian filariasis in Sri Lanka has bean completely eradicated.

\section{Entomological Aspects}

Available literature on natural and experimental filarial infections in mosquitoes in Sri Lanka is summarised in Table 1. 
Table 1. Filarial Infections in Mosquitoes of Sri Lanka.

A:

Natural infections (HUMAN AND ANIMAL FILARIAE)

MOSQUITO SPECIES

SITE OF DEV. OF

REFERENCES

FILARIAE IN

MOSQUITO HOST

1. Aedes lineatopennis

2. Aedes pallidostriatus

$-$

thorax

4. Aedes pseudomediofasciatus

5. Anopheles barbirostris

6. Anopheles "hyrcanus" nigerrimus

7. Anopheles subpictus

8. Armigeres subalbatus

malpighian tubules

fat body

55,56

9. Coquellettidia crassipes

10. Culex bitaeniorhynchus

11. Culex fuscocephala

12. Culex gelidus

13. Culex sitiens

14. Culex quinquefasciatus

15. Culex tritaeniorhynchus

16. Mansonia annulifera

17. Mansonia indiana

18. Mansonia uniformis

- $\quad$ -
malpighian tubules
fat body
$\quad-$
$\quad-$
$\quad-$
$\quad-$
thorax
$\quad-$
thorax, malpighian tubule
thorax, malpighian tubule
thorax, malpighian tubule

B : Experimentally infected with $W$. bancrofti)

14
SITE OF DEV. OF

FILARIAE IN

MOSQUITO HOST
1. Anopheles "hyrcanus" nigerrimus

2. Anopheles tessellatus thorax

thorax 
Extensive surveys of filariasis carried out in Sri Lanka from 1937 to 1939, had shown that the two types of filariasis existed at that time, the urban type due to $W$. bancrofti, and the rural type due to $B$. malayi, were localised in certain parts of the country, and its incidence (both for urban and rural type), was restricted to areas which offered the most suitable conditions for the breeding of the particular vector mosquito. ${ }^{1,2,3,4,5,6,19}$

During 1930-40's, B. malayi was the more prevalent species in areas which were usually associated with heavy infestations of water plants, mainly Pistia stratiotes, which were found in the river estuaries such as Mahaweli, Bentota river, Gin Ganga, Nilwala Ganga, and irrigational tanks in the North Western Province and the Hambantota district.

Carter $^{15}$ reported the association of immature stages of Mansonia species with 24 different plants of which $P$. stratiotes was the most important owing to its wide distribution in the endemic areas. Studies of Laurence, ${ }^{50}$ at Mahainduruwa on Mansonia breeding have shown that the main loss of the mosquito population is between the period of egg hatching and emergence to adult due to predation of these stages by other aquatic arthropods. It has also been shown that during oviposition they get more attracted to water plants already carrying egg masses of Mansonia species.

In general, $W$. bancrofti infections were restricted to congested coastal towns along the South West coastal belt, where facilities for drainage of polluted water was poor thus offering favourable sites for the prolific breeding of Culex quinquefasciatus. ${ }^{20}$ One of the earlier published documents on the biology and ecology of $C x$.quinquefasciatus in Sri Lanka is by Chow \& Thevasagayam. ${ }^{17}$ These workers have dealt in detail with the housing conditions and the breeding places of the vector in the Kurunegala district, and the effect of insecticides on the vector. Lambrecht ${ }^{49}$ has listed 15 different breeding sites in the endemic zone in Sri Lanka as favourable for Cx.quinquefasciatus breeding. This includes permanent breeding sites (catch pits, trenches, etc.) as well as man-made temporary water collections (discarded receptacles, spent nuts, etc.).

Laurence ${ }^{50}$ has shown the need for a re-assessment of the breeding sites of Cxquinquefasciatus, as some of the larval habitats recorded for breeding of the vector are in fact breeding other species of Culex and they are mistakenly sprayed with larvicides during filariasis vector control programmes. These observations are further supported by studies of Samarawickrema et. al. ${ }^{68}$ where it has been shown that coconut husk pits show a low priority for breeding of Cx.quinquefasciatus in the filarial endemic zone and larviciding of coconut husk pits had not brought about any desired reduction in the vector densities.

Samarawickrema, ${ }^{64}$ by dissecting wild populations of $C x$.quinquefasciatus collected from the filarial endemic belt, has shown that most of the transmission is effected by the adult mosquitoes that acquire the infection 
at the first blood meal. Also it has been shown that while some are able to acquire the infection in the second blood meal survive, and transmit the infection, the older populations (older than 1-parous) do not survive long enough to complete the life-cycle of the parasite.

Studies on the age composition of natural populations of Cx. quinquefasciatus in Sri Lanka carried out by Samarawickrema ${ }^{65}$ have shown that $10 \%$ to $12 \%$ of the house-resting adult $C x$.quinquefasciatus female population survived to the infective 2-parous stage, while only $11.5 \%$ of the population survived upto 3-parous stage. Daily mortality of adult mosquitoes were estimated at $13 \%-24 \%$ for a district with vector control and $18 \%-28 \%$ for an area without vector control.

An important study carried out by Samarawickrema \& Laurence, ${ }^{66}$ to investigate the parasite load of a natural population of Cx.quinquefasciatus has shown that the parasite load decreased with the age of the infection in the mosquito; the median density of microfilarial intake was 10.3 , which decreased to 2.6 by the infective stage.

Studies on filarial infections in. Cx. quinquefasciatus populations collected from human dwellings of urban, semi-urban and rural areas of the New Capital city complex Sri Jayawardenepura, by Jayasekera et. al., ${ }^{44}$ show higher densities of the adult populations in urbanised areas, which also had higher infection rates of $W$. bancrofti. Comparing these studies with those of Carter, ${ }^{15}$ it is evident that urbanization without proper sanitary engineering could lead to increase in the densities of the vector population (see section on development of new foci of infection).

Laboratory investigations carried out at the Medical Research Institute on different "strains" of the vector populations of $C x$.quinquefasciatus from endemic and non-endemic areas of Sri Lanka have established that it is one single homogenous population of $C x$ :quinquefasciatus that exist in the country. ${ }^{4,43}$ Other studies have shown that $C x$ squinquefasciatus populations of the non-endemic areas are equally susceptible to $W$. bancrofti infection, as those in the endemic areas. ${ }^{67}$

Comprehensive studies on genetic selection for a refractory strain of $C x . q u i n q u e f a s c i a t u s$ to $W$. bancrofti in Sri Lanka, and the susceptibility studies of West African (Liberian) strains of Cx.quinquefasciatus to different $W$. bancrofti strains have shown that the vector strains tested so far could not provide genes for use in the construction of a non-vector or a refractory strain intended for the replacement of Sri Lankan vector populations. Also, it was evident from these studies that the Liberian and Sri Lankan strains of $W$. bancrofti differ in their ability to infect a given strain of Cx.quinquefasciatus. ${ }^{41}$ Laboratory studies of Cx.quinquefasciatus on carriers with different levels of microfilaraemia in Sri Lanka have shown that the percentage of mosquitoes which became infected and the average number of larvae per infected mosquito were more or less directly proportional to the microfilari- 
al densities in the carriers at the time of feeding. Also, the vectors showed the ability to pick up infection from people with very low microfilaremias. $^{42,43}$

\section{Microfilaraemia}

Available records on microfilaraemia are of three categories. Firstly, the unpublished Annual Administration Reports of the AFC which contain information on the number of persons investigated, mf rates and counts on an area basis. However, the Administration Reports do not present information based on epidemiological criteria. The second category is the published reports of the $\mathrm{AFC}$, based on their routine investigations, but the latest such reports available are about 20 years old. ${ }^{1,2,3,4}$ In the third category are the results (mostly unpublished) of probe surveys carried out by investigators in the universities and research institutes.

The main filarial parasite in man in Sri Lanka is W. bancrofti. There has been a gradual decline in the mf rates since 1940's and according to AFC reports, the present rate is around $1 \%$ in the endemic areas. However in Gampaha (W.P.) and in Kurunegala, mean $\mathrm{mf}$ rates of upto $6 \%$ were reported in 1988. ${ }^{33}$ In both Gampaha and Kurunegala, there were high transmission pockets with mf rates upto $15 \%$ (Kumaratunga Mawatha, Gampaha and Wilgodawatte and Bandaranayakepura in Kurunegala- Dissanayake $\mathbf{S}_{\mathbf{S}}$. unpublished). Abdulcader and $\mathrm{Sasa}^{7}$ report an age dependent relationship for microfilaraemia. Mf rates increased with age and this tendency was very clear below 20 years of age, but less marked over 20 years. Such age/sex dependent relationship was not observed in the 1988 study: $^{33}$

One of the main objectives of the AFC, since its inception in 1947, has been the detection of new cases of microfilaraemia and DEC therapy, in the hope of interrupting the transmission. This approach has achieved only limited success as new cases are continually being detected. The follow up of microfilaraemics, specially after therapy has been almost neglected. The AFC studies ar insignificant number of treated microfilaraemics few weeks after treatment for residual microfilaraemia, by the finger prick night blood smear examination. A proper clinical investigation is rarely carried out, either before or after treatment. Under the present system, this is almost impossible as the case detection and treatment is carried out by the PHI's possibly under supervision, but not directly by a medical officer. Such follow up is extremely important because the relationship between microfilaraemia and development of clinical disease is not well understood. ${ }^{32,33}$

Residual microfilaraemia following DEC therapy does not appear to be a major problem in Sri Lanka. In the 1953 study by Dassanayake, ${ }^{21}$ it was found that oniy 5 out of the original 230 microfilaraemics had microfilaraemia (density reduced) after the 29 month treatment/follow up programme. Similarly, data from the AFC (Administration Report 1986) show that out of 2052 cases reexamined, only $62(3 \%)$ had microfilaraemia. In the 1987 study by Dissanayake ${ }^{33}$ only 1 out of $63(1.7 \%)$ had residual microfilaraemia. 
Of significance is the low level of microfilaraemia seen in a large proportion of the infected subjects. ${ }^{43}$ Such low level microfilaraemias are difficult to detect, but are probably more important in transmission of the infection. It has been reported that a high dose of microfilariae is detrimental to the mosquito ${ }^{66}$ and low microfilaraemias favour transmission. ${ }^{5}$ Carme \& Leigret $^{13}$ have observed that a patient who is amicrofilaraemic by a sensitive blood filtration technique, produced infective larvae in Aedes polynesiensis when the blood was fed. Similar observations have been made in Sri Lanka (N. Jayasekara, unpublished).

There is some evidence to suggest that microfilaraemics show an increased susceptibility to reinfection. ${ }^{3}$ It has also been reported that the normal people in filarial endemic areas show a higher degree of immune response to filarial antigens than infected subjects. $23,58,70$. This may be interpreted as reflecting a decreased immunity/increased susceptibility in the infected population. Specific immune suppression by filariae ${ }^{60}$ may contribute to the decreased immunity. It is reasonable to assume that members of a given household are exposed to infective larvae to the same extent and if only a minor proportion develop the infection, then such individuals are more susceptible than others. We have shown that microfilaraemic subjects who had been cleared of microfilaraemia by DEC therapy, are more likely to develop reinfection (increased susceptibility / decreased immunity?) than amicrofilaraemics in the same population. ${ }^{33}$. Similar observations have been reported by Dissanaike ${ }^{26}$ and Rao. ${ }^{61}$

\section{Diagnosis}

W. bancrofti infections are difficult to diagnose. Although parasitological diagnosis is the most objective, many difficulties and limitations are encountered.

Firstly, parasitological diagnosis is possible only during the microfilaraemic phase of infection which constitutes only a small segment of the infected population. The nocturnal periodicity of the microfilaraemia makes night blood examination mandatory. Obviously, night blood examination for routine investigations is difficult. The lowest level of sensitivity of blood examination by the thick smear technique is one $\mathrm{mf} /$ blood film (approximately $20 \mu \mathrm{l}$ ). The alternative nuclepore filtration technique is time consuming, needs venous blood and most importantly expensive. Although microscopic examination does provide the advantage of $\mathrm{mf}$ identification, morph $\Omega$ logical identification is not particularly important as $W$. bancrofti is the only known human parasite in Sri Lanka.

In general, clinical filariasis patients are amicrofilaraemic. Therefore, parasitological diagnosis is simply not possible. Clinical disease presents a wide spectrum and a definitive diagnosis on clinical evidence alone is difficult. However, this is one of the most difficult practical problems faced by the clinician. 
Presently available serodiagnostic tests are of two types; serum antibody determination and serum antigen determinations.

\subsection{Antibody Determinations}

The entire spectrum of antibody determination techniques (immunoelectrophoresis, counter immunoelectrophoresis, complement fixation (CFT), haemagglutination, immunoprecipitation, immunofluorescence (IFAT), radioimmunoassays, ELISA) has been applied to the diagnosis of filariasis by antibody determination, but only with limited success. ${ }^{12,32}$

We have described an ELISA using a partially purified antigen from the heterologous filariae, Setaria digitata, for the diagnosis of $W$. bancrofti infections in man. ${ }^{28,29}$ Heterologous filariae were used because the homologous parasite ( $W$. bancrofti) is not available. The very limited numbers of $W$. bancrofti $\mathrm{mf}$ that may be obtained from infected subjects is not sufficient for soluble antigen extraction and purification or use in serologic assays. The adult $S$. digitata antigen (Antigen SD2-4, ${ }^{28}$ ) had determinants in common with circulating antigens in W. bancrofti infections ${ }^{30}$ and phosphorylcholine bearing determinants. ${ }^{31}$. This antigen (SD2-4) when used in ELISA, had a good sensitivity and specificity in detecting cases of clinical filariasis who are also serum antibody positive by the indirect immunofluorescent antibody test (IFAT). ${ }^{32}$ However, the sensitivity of the ELISA with IF AT negative clinical cases was not acceptable ${ }^{32}$ (Dissanayake, unpublished data). Further; sera from the so-called non-endemic areas and from areas which were positive/endemic for brugian filariasis 3-4 decades ago, showed levels of background reactivity which were not acceptable for a diagnostic assay (Dissanayake S., unpublished data).

The above observed non-specificities were attributed to cross reactivities of the partially purified antigen SD2-4, thus implying that better specificities could be obtained by complete purification (immunochemical) of the antigen. However, more recent evidence on antigen characterizations in $W$. bancrofti and other parasites have shown that antigen non-specificity is the rule than the exception in filariae. ${ }^{53,69}$ A second possibility that was not considered at that time, was that the IFAT negative, ELISA negative clinical cases were possibly a different group by itself. Such patients are probably antibody negative by any assay (Dissanayake, unpublished data), meaning or implying some type of immune deficiency or filarial specific immunosuppression.

\subsection{Indirect Fluorescent Antibody Test (IFAT)}

The first record of the application of the indirect fluorescent antibody test (IFAT) using $W$. bancrofti microfilariae as the antigen for the diagnosis of filarial infections in Sri Lanka was by Jayawardena and Wijayaratnam. ${ }^{45}$ Although its specificity and sensitivity has never been evaluated adequately, it remains as one test available for the diagnosis of clinical filariasis.32,40 
In general the test appears to be satisfactory for chronic clinical filariasis, but in most such cases, one may not need a serodiagnostic investigation, because it is possible to make a reasonable diagnosis on clinical evidence alone. The most useful application of a serodiagnostic test is in the diagnosis of acute/atypical manifestations where clinical diagnosis is difficult. As at present, information is not available to evaluate the diagnostic potential of IFAT in atypical manifestations of W. bancrofti.infections.

It is generally accepted that antibodies to $\mathrm{mf}$ surface antigens (by conventional methods) are absent in asymptomatic microfilaraemic subjects $^{29,32,71}$ and similar observations have been reported for B. matay $i$ infections $10,18,52$ but observations with $B$. malayi may not be directly applicable to $W$. bancrofti infections. However, contrary to our previous experience $^{29,32}$ IFAT positive reactions were observed in up to $35 \%$ of asymptomatic microfilaraemic individuals, in an endemic location in Kurunegala.

The detection of IFAT positive reactions in microfilaraemics was unlikely to be due to an increased sensitivity of the test under the conditions employed, as the highest seropositivity rate observed in the same study for clinical filariasis was $65 \%$, with a $2 \%$ reactivity in the control group. Although the observed IF AT positivity in microfilaraemics contradicts the generally held view that microfilaraemics are IFAT negative, this observation indicates the need to re-examine the specificity, sensitivity and the diagnostic potential of IFAT, particularly in relation to the physical nature of the antigen employed, other parasitic infections prevalent in different geographic locations, cross reactivity of microfilarial surface antigens with antibodies to antigens of other life cycle stages of the parasite $2,51,72$ and in relation to the possibility of multiple and/or reinfections. It is also possible that some of the cross reacting antigens on the $\mathrm{mf}$ surface are in fact immunogenic in some of the microfilaraemic subjects as antibodies to certain filarial antigens are indeed present in microfilaraemic subjects. ${ }^{29}$

\subsection{Antigen Determination Assays}

The lack of acceptable specificity and sensitivity in antibody determination in the serodiagnosis of filarial infections was perhaps the primary reason for attempting to develop antigen determination assays. ${ }^{32}$

It has been argued that if there are parasites (i.e. infection), there must be parasite derived products, whose determination should provide better information than the antibody. It has also been speculated that such products would be parasite specific and life cycle stage specific, could reflect the parasite load and may even be useful in monitoring chemotherapy. However in spite of many publications using a spectrum of techniques ${ }^{31,34}$, $46,62,63$ the present state does not appear to be much different from that of antibody determination assays. 
We have used a mouse monoclonal antibody raised against Onchocerca gibsoni (prepared by Dr. K. Forsyth) egg antigens with its determinant as Phosphorylcholine anti PC) in an immunoradiometric assay for the measurement of circulating antigens in serum and in urine. ${ }^{31}$ Circulating antigens were detectable in both microfilaraemic and amicrofilaraemic clinical cases, but mostly in the microfilaraemics. The test was useful in detecting infection in microfilaraemics, particularly the high mf density ones. Among the amicrofilaraemics, $47 \%$ of those with lymphoedema, lymphangitis hydrocoele, etc, and $25 \%$ of those with elephantiasis had circulating antigen by this assay. The assay was not capable of specifically diagnosing/detecting $\mathrm{mf}$ positives as some of the clinical cases were also positive.

Sufficient data is available to conclude that filarial antigens and antibodies show both quantitative and qualitative differences in the levels and immunoreactivities in relation to geographic location of the source material. It appears that most serologic assays show a higher degree of sensitivity in India $38,7.5$ while such high sensitivities are not seen in Sri Lanka (Dissanayake, unpublished). In Sri Lanka, the prevalence of antibodies to $W$. bancrofti micro filarial surface antigens in microfilaraemic and amicrofilaraemic subjects too appear to be different in different geographic areas. IF AT positive reactions were observed in microfilaraemic subjects in Gampaha and Kurunegala. ${ }^{3}$ Hyperimmune human anti-filarial sera from different countries $(W$. bancrofti $\mathrm{mf}$ positive cases from India, Sri Lanka and Malaysia) were different with respect to anti-filarial activity (TDR/FIL/ MAB-DIAG/83-3, unpublished document of the W.H.O., page 12). Similarly, the anti-phosphorylcholine (anti-PC) monoclonal antibody of Forsyth et. al. ${ }^{34}$ showed different reactivities with sera from Papua New Guinea (PNG), Kenya, Sri Lanka and the Phillipines. In a two site immunoassay for circulating antigens, this anti-PC antibody showed very good sensitivity with PNG and Kenya sera, but the sensitivity with Sri Lanka and Phillipine sera was very low. ${ }^{38}$

The pattern of disease also appears to differ with respect to geographic location. A well defined pattern from pre-patent to acute state culminating in chronic disease is seen in Indonesia 59 whereas such clearly defined patterns are not seen in Sri Lanka. ${ }^{33,40}$ Similarly a high prevalence of microfilaraemics with clinical disease is also reported from PNG. ${ }^{47}$ In Sri Lanka, microfilaraemics rarely show clinical disease. ${ }^{33}$ In India, it has been reported that areas with high average $\mathrm{mf}$ counts had higher disease rates. Further, in Kerala, Karnatake and Andra Pradesh, elephantiasis of lower limbs was predominant while genital lesions were more common in Uttar Pradesh and Bihar. ${ }^{61}$

It would be reasonable to extrapolate the above findings to different geographic locations within the same country and/or diffęrent locations in the same endemic area. The development of an antigen determination test applicable to large and geographically different populations would therefore be very difficult. 
In conclusion, it may be said that contrary to expectations, antigen determination may not be the final answer to serodiagnosis of bancroftian filariasis. Antibody determination may be more applicable in some of the clinical states. Therefore, base line information on epidemiology, serology and clinical disease is needed prior to development and evaluation of antigen determination assays.

\section{Development of Netw Foci of Infection}

During the last 50 years, bancroftian filariasis in Sri Lanka has shown a gradual spread. Surveys by Dassanayake (1937-39) showed only two foci, in Galle and Matara towns. In 1947, the entire South Western coastal belt extending from Negombo to Matara was endefic. In 1967/68, new foci were reported in Kandy, Kurunegala, Kataragama, Chilaw and Tangalle. ${ }^{24}$ The presently available data (AFC) shows that the disease is endemic in the Western coastal belt extending from Puttalam to Kataragama.

Abdulcader and Sasa ${ }^{7}$ attributed the spread of W. bancrofti in 1940's to a build up of $C x$.quinquefasciatus populations consequent to the construction of approximately 3000 latrine catch pits resulting from urbanization which occured after the introduction of a Health Unit System of 1926 and to the presence of foreign troops with microfilaraemia in South West Ceylon. However, these claims had not been supported adequately with epidemiological evidence.

According to Lambrecht ${ }^{49}$ movement of infected people to and from the endemic to non-endemic areas is possibly a significant contributory factor for the spread of filariasis. The vector, Cxquinquefasciatus is present almost all over the island and when $C x$. mosquitoes collected from 28 different locations were dissected, low levels of infections were detected in many areas. In 1972, it was estimated that approximately 1.5 million people were travelling between endemic and non-endemic areas and the would-be present mf carriers in this population, it was predicted, be sufficient to infect the Culex mosquitoes in the non-endemic areas. Today, 15 years later it is most likely that this source of infection to the mosquito has tremendously increased. However, the climate is likely to be one deterrant. For example, development of the parasite to the infective stage does not appear to take place in Nuwara Eliya and in Jaffna. ${ }^{4}$

For the development of new foci of infection, three criteria need to be satisfied:

1. environmental conditions conducive for the breeding and propagation of the vector, Cx.quinquefasciatus.

2. presence of microfilaria carriers for the infection of the mosquitoes

3. a susceptible human population. 
In Sri Lanka, as at present, two major development programmes can be identified which have the potential to satisfy the above criteria. Of these, the more important is the Accelerated Mahaweli Irrigation Scheme and secondly, the development of clusters of semi urban houses under the housing programmes of the present governmant.

The primary effect of water reservoir development is in the establishment of the vector and host-vector contact. In Table 2 are summarised the events that lead to this development of host vector contact.

The presence of $C x$.quinquefasciatus, in significant numbers, in some of the Mahaweli areas is already documented. Herath et. al. ${ }^{39}$ have collected 14 species of Culex, including Cx.quinquefasciatus, from Mahaweli System $C$ and Kirinde Oya and this was one of the more dominant species collected. Amerasinghe ${ }^{11}$ has reported Cx.quinquefasciatus from Dehiattakandiya in Mahaweli System C, but with low biting rates. W. bancrofti infections have been detected in Cx.quinquefaciatus in Mahaweli System C. ${ }^{39}$ ?

Microfilaraemic subjects among the immigrant workers of the Mahaweli System $\mathrm{C}$ are also reported. Vitarana et. al. ${ }^{74}$ have found 2 such $\mathrm{mf}$ carriers in System C (infection rate 0.09\%) and 1 from Kirindi Oya (infection rate $0.14 \%$ ). These authors have reported infection rates ranging from $0.03 \%$ to $0.18 \%$ in Tissamaharama/Lunugam Vehera areas. 
等|

吕|

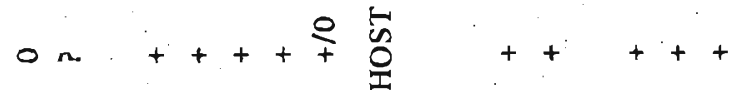

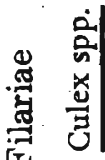

i.

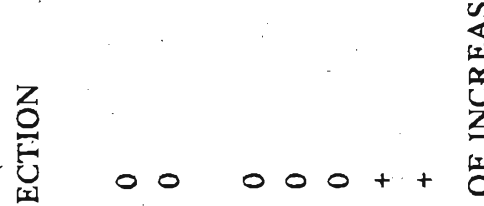

鳏.

善

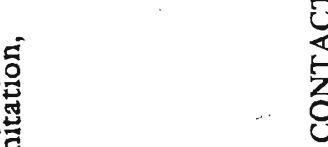

닝

茛

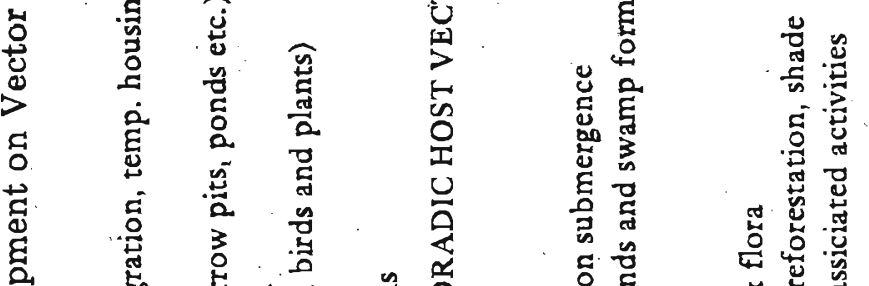

范

๑े टे

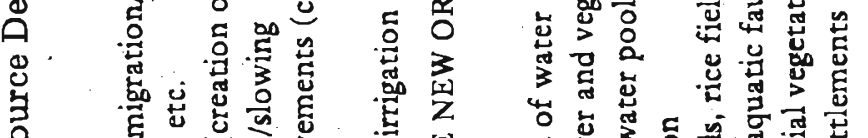

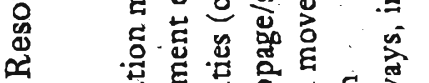

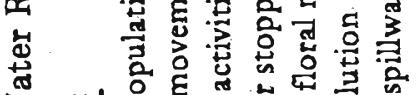

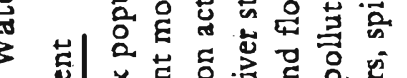

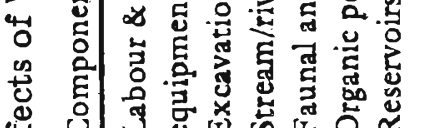

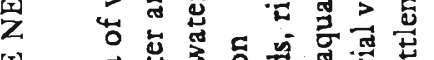

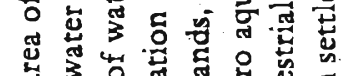

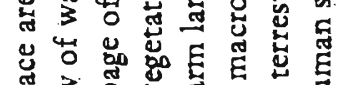

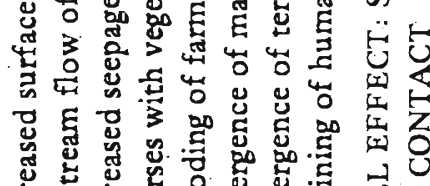

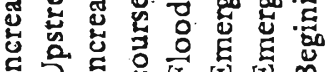

出

i $-i$ intio

年

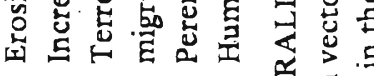

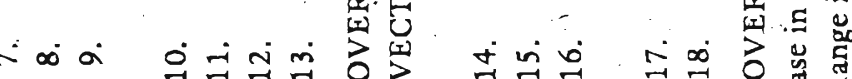

离离

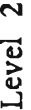

m 


\section{Control Strategies}

In Sri Lanka, as in many other developing countries, where filariasis is endemic, control is attempted by conventional methods; vector control by larvicide/adulticide spraying and interruption of transmission by chemotherapy of mf carriers. Both methods are labour intensive.

\subsection{Vector control by larvicide/adulticides}

How effective and/or feasible is this approach? Superficially, it appears to be effective and many would argue in favour of it. Often, the success story of the control of Brugian filariasis in 1940-50's is cited as supportive evidence. $C x$. quinquefasciatus, the vector of bancroftian filariasis, behaves differently. It breeds in discarded receptacles, trenches, burrow pits, unused wells, coconut and arecanut pits, latrine pits, etc. Some of these places are impractical to spray and some others, cannot be sprayed for danger of poisoning of the human population. The adult rests on wall hangings, curtains, hanging cloths, but rarely on walls. Therefore, spraying of insecticides inside houses is not practical. The overall effect is that only about $20 \%$ of the Culex larvae and adults could be controlled by this approach.

Modern research technologies (McABs, recombinant DNA, etc) are indeed helpful in many ways in the development of control strategies. Species and life cycle stage specific McABs could help in the development of immunological techniques for the identification of infective larvae in mosquitoes (otherwise not possible on morphological characteristics), development of specific and sensitive immunodiagnostic techniques, in the purification of antigens, etc. Two valuable applications of recombinant DNA technology in filariasis control is the production of protein antigens by the use of expression vectors and probes for identification of species. Collaborative research projects (S Dissanayake, E. Karunanayake \& N. Jayasekara) covering these aspects are in progress.

\section{Filariasis Control and AFC in Sri Lanka}

The AFC was established by the government in 1947, for the sole objective of controlling filarial infection/disease in Sri Lanka. It functions under a Superintendent (Medical Officer), who is the chief administrative authority. The activities/services of the AFC reach the general public through a network of PHI's and Field Assistants (FAs). The PHI's and FA's are expected to perform a multitude of activities (under direction and supervision of the AFC and the M.O.H. of the area) ranging from health education, night blood filming, maintenance of records, distribution of drugs to $\mathrm{mf}$ carriers and conduct of clinics for clinical patients. In fairness to the AFC and it's staff, it must be stated that the AFC functions under very severe constraints, particularly, non-availability of sufficient funds and facilities for routine work. 
Successful control of filariasis in Sri Lanka by conventional methods, particularly new case finding and treatment (interruption of transmission) is certainly possible. The success story of Brugian filariasis in. Sri Lanka in 1945-55 is perhaps the best supporting evidence. In other countries too, similar successes have been achieved. In the Kuroshima island of Japan, by selective administration of DEC over a period of 13 years, (1967-80), the $\mathrm{mf}$ rate has been brought down to $0 \%$ from $13.2 \% .^{73}$ The improvement of sewerage/organic matter disposal is considered as the primary cause of disappearance of bancroftian filariasis from Charleston, South Carolina. ${ }^{16}$ The best example of mobilization of the endemic populations in the control of filariasis is perhaps from Indonesia. ${ }^{59}$

\section{Conclusions}

The primary objective of this review was to focus attention on aspects that need an increased input of effort. It reflects the fragmentary nature of the little information available. Of prime importance are studies on epidemiology of microfilaraemia, clinical disease and the relationship between the two. Follow up study of treated microfilaraemics is a must. Also needed are investigations on the vector, breeding habitats and more effective methods of control. It would be worth while to quantify the capacities of different mosquito species to transmit human and animal filariae.

The AFC, through it's network of field workers, probably collects a wealth of information and if these data are presented in a more scientific and on statistical/epidemiological criteria, it could fill considerable gaps in knowledge.

There is a complete vacuum in the infotmation available on the clinical aspects. The spectrum of clinical disease is likely to be much wider than and different from what is known now. For example, classical presentations such as elephantiasis and hydrocoeles are probably on the decline, but other forms such as arthritis, athralgia, nodules, skin reactions, nephritis/ nephrotic syndrome, etc., are likely to be more common and more important.

Government ministries responsible for Housing, Urban Development, Lands and Irrigational Development must take special note of the possibility of introducing new foci into areas which are presently non-endemic.

\section{Acknowledgements}

We are thankful to Dr. H. Gauthamadasa, Director, Anti-Filariasis Campaign, Sri Lanka for her comments and suggestions in the final phase of the preparation of this manuscript. 
This study received financial support from the International Development Research Centre, Canada (grant to S.D.). Secretarial assistance by Miss. S. Kapuwatte is acknowledged.

\section{References}

1. ABDULCADER, M.H.M. (1961) Journal of Ceylon Public Health Association 2 (New Series): 100

2. ABDULCADER, M.H.M. (1962) J.Trop. Med. Hyg. $65: 298$

3. ABDULCADER, M.H.M. (1964) I.Trop. Med. Hyg. 67-71.

4. ABdulCAdeR, M.H.M. (1965) Cey. Med.J. March 1965, p64-66

5. ABDULCADER, M.H.M.; RAJAKONE, P., THARUMARAJAH, K. \& MAHADEVA, R. (1965) J. Trop. Med. Hyg. $68: 254-256$

6. ABDULCADER, M.H.M., ANTONIPULlE, P., JEYARATNAM, P.G. \& RAJENDRAN, K. (1966) Bull. Ind. Soc. Med. Com. Dis. 3(4) : 345-6.

7. ABDULCADER, M.H.M. \& SASA, M. (1966) Japan J. Exp. Med. 36(6) : 609-646.

8. ADMINISTRATION REPORT OF ANTIFILARIASIS CAMPAIGN (1986)

9. ABEYWIKRAME, W. \& ISMAIL. M.M. (1985) Mosquito Borne Dis Bull 1(4): 89-90

10. AgGRawal, A., CUNA, W., HAQUE, A., DISSAUS, C. \& CAPRON, A. (1985) lmmunology, $54: 655-663$.

11. AMARASINGHE, F.P. (1986) Proceedings of the Workshop on Irrigation and Vector - Borne Disease Transmission. International Irrigation Management Institute, Digana Village, Sri Lanka. p. 14-21.

12. AMBROISE THOMAS P. (1974) Acta Tropica. $31: 108-128$.

13. CARME, B. \& LEIGRET, J. (1979) Am.J. Trop. Med. \&Hyg. 28: 53-58.

14. CARTER, H.F. (1948) Ann. Trop. Med. parasit $42: 312-32$.

15. CARTER, H.F. (1950) Cey.J. Science B, $24: 1$.

16. CHERNIN, E. (1987) AmJ Trop. Med. Hyy. 37(1):111-4.

17. CHOW, C.Y. \& THEVASAGAYAM, E.S. (1957). Bull. WH(), $16: 609-632$.

18. CRANDALl, R.B., CRANDALl, C.A., NEILSON, J.T., FLETCHER, J.T., KOZEK, W.W. \& REDDINGTON, B.. (1983) Acta Tropica (Basel), $40: 53-64$.

19. DASSANAYAKE, W.L.P. (1938) J. Trop. Med. 11yg. $41: 141$.

20. DASSANAYAKE, W.P. (1955) W.H.O/FIL/14 Deccmber 1955.

21. DASSANAYAKE, W.L.P. \& CHOW, C.Y. (1954) Annals Trop. Med. Parasit $48: 129$. 
22. DENHAM, D.A., MCGREEVY, P.B., SUSWILO, R.R. \& ROGERS, R. (1983) Parasitology, $86(1): 11-18$.

23. DESOWITZ, R.8., BERMAN, S.J. \& PULOKA, T. (1976) Bull WHO 54 : 565-571.

24. DISSANAIKE, A.S. (1968). Proceedings of "Seminar on filarizsis and immunology of parasice infections and laboratory meeting" Editors Sandosham AA and Zaman A. Singapore 1968.

25. DISSANAIKE, A.S. (19792). Bull. WHO $3: 349-357$.

26. DISSANAIKE, A.S. (1979b) Unpublished document Bi regional research study group mecting on Culex-borne bancroftian filariasis. New Delhi 19-23. November 1979 ,

27. DISSANAYAKE, S., de SILVA, L.V.K. \& ISMALL, M.M. (1980) Trans. R. Soc. Trop. Med. Hyg. 74(4) : 542-544.

28. DISSANAYAKE, S. \& ISMAIL, M.M. (1980) Bull. WHO 58(4) : 649-654.

29. DISSANAYAKE, S. \& ISMAIL, M.M. (1981) Bull WHO 59(5) : 753-757.

30. DISSANAYAKE, S., GALAHITIYAWA, S.C. \& ISMAIL, M.M. (1982) BuIL WHO 60(6): 919-927.

31. DISSANAYAKE, S., FORSYTH, K.P., ISMAIL, M.M. \& MITCHEL, G.R. (1984) Am.J. Trop. Med. Hyg. $33: 1130-1140$.

32. DISSANAYAKE, S. \& ISMAIL, M.M. (1987) Ciba Foundation Symposium no 127 p 203-213

33. DISSANAYAKE, S. (1988) Trans. R. Soc. Hyg. Trop. Med. (subhitted).

34. FORSYTH, K.P., SPARK, R., KAZURA, J., DISSANAYAKE, S. \& MITCHELL, G.F. (1985) J. Immunol; $134: 1172-77$.

35. FORSYTH, K.P. (1987). In "Ciba Foundation Symposium no 127" page 213 Wiley Chichester.

36. GROVE, D.I. (1981) South East Asian J. Trop. Med. Pub. Hltb 12(4): 487-91.

37. GROVE, D.I. \& DAVIES, R.S. (1978) Am. J. Trop. Med. \&Hyg. 27 : 508-513.

38. HARINATH, B.C. (1987). In "Ciba Foundation Symposium no 127" page 214-6. Wiley Ohichester.

39. HERATH, P.R.J., JAYASEKARA, N., KALPAGE, K.S.P., WICKREMASINGHE, M.B., GUNATILAKE, V. \& NANAYAKKARA, W.M. (1986): Proceedings of the Workshop on Inigation and Vector-Borne Disease Transmission. 22-32.

40.

ISMAIL, M.M. \& DISSANAYAKE, S. (1981) Clinical picture and diagnosis of occult etyptic amicrofilataemic infections (unpublished). Sixth SWG Meeting on lymphatic filariasis WHO/ TDR Colombo.

41: JAYASEKARA, N., CURTIS, C.F., LIELKE, E., KUTTLOW, F., JANSEN, C.G. \& CHELLIAH, R.V. (1980). Tropenmedizin and parasitilogie, 31 : 5़07-511.

42. JAYASEKARA, N., SAMARAWICKREMA, W.A., JANSEN, C.G. \& CHELLIAH,R.V. (1981 a)J . Natn. Sci Coun. Sri Lanka 9(2) : :177-182. 
43. JAYASEKaRA. N., de SILVA, C.S.S., MUNASINGhe, C.H., ehELliA, R.V: \& SAMARAWICKREMA, W.A. (1981b). Working paper:WHO workshop on diagnosis of infection and evaluation of control of lymphatic filariasis - Oct. 1981 :

44. JAYASEKARA, N., CHELliaH, R.V., JANSEN, C.G. \& PATHMANATHAN, S. (1986) Mosquito-Borne Dis. Bull, 2(4): 87-93.

45. JAYAWARDENA, L.G. \& WIJAYARATNAM, Y. (1968)J, Helmintbs 42: 57-64.

46. KALIRAJ, P., KHARAT; I., CHIRMIKAR, S.N. \& HARINATH, B.C. (1981)J. Helmintbol; $55: 133-39$.

47. KAZURA, J.W., SPARK, R., FORSYTH, K., BROWW, G., HEYWOOD, P., PETERS, P., ALPERS, M. (1984) Am. J. Trop. Med. Hyg. 33(6) : 1119-23.

48. KYNSEY, W.R. (1892) Ceylon Administrative Report Part IV A 53.

49. LAMBRECHT, F.L. (1974) BulI WHO $51: 133-143$.

50. LAURENCE, B.R. (1965). WHO/Vector Control/159-65.

51. LIE, K.J. (1962) Am.J. Trop. Med. \& Hyg. $11: 646-652$.

52. MCGREEVY, P.B., RATIWAYANTO, S., TUTI, S., MCGREEVY, M.M. \& DENNIS, D.T. (1980) Am.J. Trop. Med. \&Hyg. $29: 553.562$.

53. MAIZElS, R., BURKe, J., SUTANTO, I., PURNOMO, PARTONO, F. (1986) Mol. Biochem. Parasitol. $19: 27-34$.

54. NILES, W.J. \& SAMARAWICKREMA. W.A. (1956) Trans. Roy. Soc. Trop. Med. \& Hyg. $50:$ (11) 182-183:

55. NILES, W.J. (1962) Trans. Roy. Soc. Trop. Med. \&Hyg. 56(5): 437-438.

56. NILES, W.J. (1966) Cey.J. Med. Science. $15: 41-44$.

57. ONDATJE, W.C. (1879) Ceylon Administrative Report. Appendix No. 2,255 C.

58. OTTESEN, E;A., WELleR, P.F., LUNDE, M.N., \& hUSSAIN, R. (1982) AmJ. Trop. Med. \&Hyg. 31 : $953-961$.

59. PARTONO, F. (1987) Ciba Foundation Symposium No. 127. p. Wiley Chichester.

60. PIESSENS, W.F., WADEE, A.A. \& KURNIAWAN, L. (1987) Ciba Foundation Symposium, 127. 173. Wiley Chichester.

61. RAO; C.K. (1977) . Comm. Dis. 9(4): 185-91.

62. REDDY, MV.R., HARINATH, B.C. \& HAMILTON, R.G. (1984a) Indian J. Exp. Biol; 22 : 515-19.

63. REDDY, M.V.R., MALHOTRA, A. \& HARINATH, B.C. (1984b)J . Helmiqgthol; $58: 259-62$.

64. SAMARAWICKREMA, W.A. (1962) Bull. WHO. $27 ; 637-640$.

65. SAMARAWICKREMA, W.A. (1967). Bull. WHO $37: 117-137$. 
66. SAMARAWICKREMA, W.A. \& LAURENCE, B.R. (1978) Ann. Trop. Med. Parasitology 72(6): $561-565$.

67. SAMARAWICKREMA, W. A. JAYASEKARA, N., CHELLIAH, R.V. \& JANSEN, C.G. (1981) J. Natn. Sci. Coun. Sri Lanka, $9(2): 171-176$.

68. SAMARAWICKREMA, W.A., JAYASEKARA, N., JANSEN, C.G., CHELLIAH, R.V., KARANDAWALA, F.R. \& PATHMANATHAN, S. (1982). Soutbeast AsianJ. Trop. Med. Pub. Hlth, 13(4) : 590-595.

69. SELKIRK, M.E., DENHAM, D.A., PARTONO, F., SUTANTO, 1. \& MAIZELS, R. (1986) Parasitology: 91(5): 5-538.

70. SIM, B.K.L., MAK, J.W. \& KWA, B.H. (1983) Zeitscbrift Fur Parasitenkunde (Berlin), 69 : 371-375.

71. SIMONSEN, P.E. (1985) Trans. R. Soc. Trop. Med. \& Hyg. $79: 852-858$.

72. STEWARD, M.W., SISLEY, B., MACKENZIE, C.D. \& EL SHEIKH, H. (1982) Clin. Exp. Immunol, $48: 17-21$.

73. TADA, I., OTSUJI, Y., HARADA, R., MIMORI, T. \& FUKUMOTO, H. (1982) Am. $\mathrm{f}$ Trop. Med. Hyg. 31(5) : 962-7.

74. VITARANA, T., HERATH, P., KA LPAGE, K., JAYASEKARA, N., WICKREMASINGHE: M. \& GUNATILAKE, V. (1986) Proceedings of the Workshop on Irrigation and Vector - Borne Disease Transmission. International Irrigation Management Institute, Digana Village, Sri Lanka. P. 9-14.

75. WELL, G; J. KUMAR, H., SANTHANAM, S., SETHUMAHADEVAN, K.V.P., \& JAIN, D.C. (1986) Amer.J. Trop. Med. Hyg; 35(3): 565-70.

\section{Relevant literature not listed in text}

BAHR, P.H. (1914) Parasitology 7 : p. 128.

CHAN, S.H., DISSANAYAKE, S., MAK, J.W., ISMAIL, M.M.; WEE, G.B., SRINIVASAN, N., SOO. B.H. \& ZAMAN, V. (1984). Soutb East AsianJ. Trop. Med. Pub. Hith. 15(3): 281-286.

CHANDRASOMA, P.T., MENDIS, KN. \& KUMARARATNE, D.S. (1977). Am J. Trop. Med. Hyg. $26: 570-71$.

CHANDRASOMA, P.T. \& MENDIS, K.N. (1978). AmJ . Trop. Med. Hyg. $27:$ 770-773.

DISSANAYAKE, W.L.P. (1953). Annals Trop. Med. Parasitol $48: 123-128$.

DISSANAYAKE, S., GALAHITIYAWA, S.C. \& ISMAIL, M.M. (1983) Bull WHO 61(4); 725-730.

ISMAIL, M.M. \& NAGARATNAM, N. (1973) Trans. R. Soc. Trop. Med. Hyg. $67: 405-409$.

ISMAIL; M.M. \& DISSANAYAKE, S. (1981). Unpublished document WHO TDR FIL SWG (6)/81 SWG Meeting, Colombo, Sri Lanka.

JAYASEkara, N. \& CHELliah, R.V. UNesCo:Man Biosphere National Commitee. Pub, no 8. NARESA SL. 
JAYAWARDENA, L.G. (1962)J. Helmintbos 36(3) : 269-80.

JAYAWARDENA, L.G., ISMAIL, M.M. \& WIJAYARATNAM, Y. (1965) Ceylonj. Med. Sci, 14 : 36-48.

NAGARATNAM, N. \& ISMAIL, M.M. (1973) Trans. R. Soc. Trop. Med. Hyg. $67: 803-807$.

WALlOOPILIAI, N.J. \& ATUKORALE, R.P. (1973)J . Colombo Gen. Hosp. 4 : 24-29.

WIJETUNGE, H.P.A. (1967)J . Trop. Med. Hygiene 70 : 25-28. 